\title{
Call for Submissions for the 1990 APA Convention
}

\author{
Veronica Tonay Division 32 Program Chair
}

Theme: Diverging Roads in a Dark Wood

As Division Program chair for the 1990 APA Convention in Boston, I would like to take this opportunity to invite you to participate in the upcoming program. Now, perhaps more than ever, a humanistic influence in psychology is needed. With the current identity confusion within the APA reflecting the growing split between research and applied orientations, some have gone so far as to say that psychology is in danger of losing its soul.

Division 32 represents a diverging road in the "dark wood" of present-day, mainstream psychology. The Program Committee's goal for 1990 is to assemble a diverse program which reflects the human importance of its presentations. In order to prevent our divergent road from becoming impassable through neglect, I urge you to submit a presentation for the upcoming convention.

You may participate in the traditional way, by presenting a paper on humanistic theory, research (including case studies, psychobiography, psychotherapy research, etc.), or therapeutic technique. You may also organize a symposium on a topic of interest. Paper presentations are alloted 20 minutes each by the APA. Symposiums last 90 minutes. We plan to hold several discussion hours and workshops in the Hospitality Suite, for which we welcome suggestions. Finally, we welcome appropriate proposals of a non-traditional nature. Some examples are theatrical presentations, films, or audience-participatory submissions. Possible topics for all submissions are: humanistic education, medicine, therapy; creativity; humanistic approaches to dreams; contributions of prominent humanistic psychologists; social concerns; global perspectives; the future of humanistic psychology.

Early proposals are appreciated. The deadline for proposals is December 15, 1989. Please send five copies to: Veronica Tonay, 223 Walnut Avenue, Santa Cruz, CA 95060.

Even if you do not choose to participate, your attendance is important. In addition to the program's exciting scholarship and networking opportunities, attendance at the convention can provide us with a sense of community as humanists. We are planning to make the 1990 convention a dynamic and memorable one. I look forward to seeing you there! 